\title{
Britain awaits impact of 1993 reforms
}

London. In few countries was the transition of science policy in 1993 marked as clearly as in Britain, where the publication in May of the government's white paper (policy document) on science and technology proved, as previously anticipated, to be a turning point in the country's approach to the organization of science.

The white paper was broadly welcomed, even by those who disagreed with some of its conclusions, as the first governmentwide statement of science for almost 20 years. It was also seen as an explicit acknowledgement of the political importance of research in a competitive global economy.

But the document's impact lay less in its relatively straightforward message - that science deserves continuing support from public funds primarily as a source of longterm wealth, rather than as an unrestricted search for new knowledge - than in the procedures it proposed for carrying these out.

Three changes stand out. The first has been the reorganization of the research councils - in particular the splitting up of the former Science and Engineering Research Council - giving each new council a clear mission which makes explicit their responsibility towards the nation's economic health.

The second has been the decision to integrate the management of the research councils into the functioning of government by making them responsible to the holder of the new post of director general within the

\section{Commercialization is the word in India}

New Delhi. 1993 was a bad year for Indian science. Budget cuts, inflation and the devaluation of the rupee left research institutions with a reduction of 20 to 30 per cent in research funds. No new major projects were launched, and the country's largest research body, the Council of Scientific and Industrial Research, was only just able to pay salaries and electricity bills.

This year may be better. It is unlikely to see an increase in taxpayers' money going to publicly funded laboratories. But more money may come from industry. A new technology policy to be introduced early in the year requires each company to place a percentage of its annual turnover in a research and development fund.

In the public sector, projects will receive funding only if they yield marketable products, says S K Joshi, chief of CSIR. Two factors have led to this approach: liberalized economic policies, which have increased competition; and the revisions to the General Agreement on Trade and Tariffs, which will now prevent Indians from copying products developed by others. K. S. Jayaraman
Office of Science and Technology.

The third has been a broad-based exercise in crystallizing thinking about the country's technological objectives, known as "technology foresight" and designed to make the research community aware of where industry (and government) would like its future priorities to lie.

Government officials claimed at the end of the year that the political success of the white paper was demonstrated by its effectiveness in helping to ward off the Treasury's efforts to impose major cuts in public spending on research.

Industry, too, which is now being offered a greater role then ever in determining the country's research agenda, gave its general endorsement. Its main reservation was that it had not been sufficiently consulted over, for example, proposals for a four-year research doctorate or technology foresight priorities (both of which the government moved hastily to rectify).

Scientists were more cautious. With no promise of extra funding, and strong evidence of greater external control over how funds are to be spent, there was little concrete to delight scientists.

But it could have been worse. "What has come out is seen as moderate, potentially beneficial and certainly better then might have been expected" says Sir Michael Atiyah, president of the Royal Society.

1994 will tell how much of this potential

\section{Canada promised a new boost for R\&D}

Ottawa. Canada's science policy in 1993 was dominated by the change of government, and the promises made by the Liberal party before the election seem certain to set the policy directions for the new year.

Soon after the election, Jean Chrétien, the new prime minister, reaffirmed his intention to introduce a series of measures designed to boost research and technology in Canada, despite a budget deficit $\mathrm{C} \$ 5$ billion (US $\$ 3.8$ billion) higher than the previous government's forecast.

The measures include doubling investment in research and development, with emphasis on small and medium-sized businesses, provided Canada shows it can manage the increase. Technology networks would be established between universities, industry and government and co-operation and partnerships encouraged between them.

Chrétien said that the new government will also continue to support basic research, to include "stable funding for the granting councils, the National Research Council, and the Networks of Centres of Excellence".

David Spurgeon benefit will materialize. It will also show whether the changes being sought by the government are sufficiently widely accepted to survive future short-term shifts in national priorities.

In the immediate future, both the new research councils and the higher education funding councils face the task of devising an effective measure of the potential usefulness of strategic research (rather than merely scientific merit) that can be used to judge individual grant applications.

Many researchers are worried that excessive heavy handedness in applying costbenefit analysis to do this, however sophisticated, will stifle long-term creativity. "As in physics, there is a danger that if you start observing a system too closely, you may interfere with its effects" says Atiyah.

A different challenge facing the government is how far its commitment to market forces should apply to institutions such as the National Physics Laboratory and the Laboratory of the Government Chemist, each founded on the philosophy that there are some national needs which the market is unable or unwilling to address.

"This is the dark side of the white paper," says Valerie Ellis, deputy general secretary of the Institute of Managers, Professionals and Specialists, which has expressed alarm at recent reports that many of these laboratories are going to be fully or partially privatized in the near future. David Dickson

\section{Australian scientists feel the heat}

Sydney. The Australian government's longstanding policy to make all the money it spends on science outside the universities count towards economic growth was further consolidated during 1993.

One element of this strategy was increased pressure on the government's main research organization, the Commonwealth Scientific and Industrial Research Organization (CSIRO), to find more of its budget from the industries it was formed to serve. Thus its budget was cut by 1.3 per cent, and a special annual grant of \$A50 million has come under threat.

In contrast, Co-operative Research Centres (CRCs) received more money. These are joint industry-university research centres designed to improve the commercialization of academic inventions and to stimulate industry-orientated research. More than 50 are planned.

For those scientists uninterested in commercial research there was some good news; the Australian Research Council received a 7 per cent increase in funding, to $\mathrm{A} \$ 294$ million.

Mark Lawson 